Another of the more interesting variables, $\chi$ Cygni, may be expected at a maximum about November 15 , and $\mathrm{R}$ Leporis, "the crimson star," at a minimum on January 5.

The Double-Star 99 Herculis.-Mr. S. W. Burnham, in his last Catalogue of double-star measures, refers to a statement by $\mathrm{M}$. Flammarion to the effect that the change in the position of the companion of 99 Herculis (one of Alvan Clark's discoveries) very nearly corresponds to the proper motion of the large star. But although the alteration in position between Dawes' measures in 1859 and Mr. Burnham's in 1880 , may be fairly represented by rectilinear motion, it will hardly appear, when the best value we can assign at present for the proper motion of 99 Herculis is introduced, that it accounts for the observed change in the position of the companion. If we compare Bradley for 1755 with the Greenwich Catalogue for 1864 , employing the accurate formulæ, we find :-

Secular proper motion in right ascension ... $-\mathrm{II}^{\prime \prime} \cdot 34$

$$
, \text {, , , declination } \ldots+6^{\prime \prime} \cdot 90
$$

Mädler assigned for the respective proper motions $-\mathrm{IO}^{\prime \prime} \cdot 4$, and $+7^{\prime \prime} \cdot 0$.

Taking for comparison the following meastres of 99 Herculis, Position Distance

$\begin{array}{rrrrrrl}1859^{\circ} 63 & \ldots & 347^{\circ} \cdot 2 & \ldots & I^{\prime \prime} 705 & \ldots & \text { Dawes } \\ \mathbf{1} 880^{\circ} \cdot 18 & \ldots & 29^{\circ} 9 & \ldots & 0^{\circ} 9 \mathbf{r} & \ldots & \text { Burnham }\end{array}$

we find on bringing up Dawes' measures to Burnham's epoch, with the proper motions of the principal star given above, the angle of position becomes $8 I^{\circ} \cdot 5$, and the distance $I^{\prime \prime} \cdot 65$, showing a great difference from the result of the American astronomer. It seems at least probable, as he remarks, that it will prove to be a physical pair.

\section{THE WATER SUPPLY CONFERENCE}

THE Water Supply Conference of the Society of Arts, held at the National Health Exhibition, in the unavoidable absence of the President, H.R.H. the Prince of Wales, was opened by Sir Frederick Abel, C.B., F.R.S., chairman of the Council, who alluded in his introductory address, to these Congresses having been originated by His Royal Highness, who hoped a comprehensive scheme might be elaborated that would provide not only for the urban populations, but for the rural communities. He alluded to the good and useful work done by the Congress held in 1878 , and in 1879 , and reviewed the present position of the water-question in this country.

The papers read at the Conference were placed under three heads, viz. :- " "sources of sufply," "quality of water, with methods of filtration and softening," and "methods of distribution, with modes of giving pressure, house fittings, discovery and prevention of waste." Under all heads valuable papers were contributed, and the Society may again be congratulated on bringing together a jury of experts capable not only of showing us the weak points in our existing water-supply, but the methods by which these defects may be remedied. This was done to a large extent by the previous Conference, but the dangers then pointed out have been hardly appreciated, owing to the years of the Conference being followed by a remarkable succession of wet seasons. Now that a hot summer is succeeding a dry winter, the gravity of the situation is forcing itself upon public attention, and the importance of hushanding our water resources is found to be a matter of vital necessity, the neglecting of which has already facilitated the spread of English cholera, in certain districts, and will be a constant element of danger, should Asiatic cholera appear on this side of the English Channel.

Rainfall being the source of all water supply, it may be well to first notice the paper contributed by Mr. G. T. Symons, F.R.S., who, just a quarter of a century ago, instituted the first general series of rainfall observations ever made in this country, and who since that time has been gradually increasing their number, until there are now nearly 3000 observers, no less than 2433 stations having furnished perfect records of rainfall last year. Worthy of all praise as is this remarkable voluntary staff of observers, not only giving their services, but actually contributing 99 per cent. of the cost of publishing the observations made, it is obvious, looking to the direct bearing such observations have on engineering, agricultural, and sanitary questions, bearing on the health and welfare of our population, that the scope of the inquiry should be enlarged so as to increase its sphere of usefulness, and that it should be placed under a
Government department with a grant from Parliament, and the inquiry be no longer crippled for want of funds as regards possible and necessary extensions, though ten years ago the British Association for the Advancement of Science, feeling it their duty to initiate, rather than support, investigations of national importance, withdrew the vote with which they had aided the work for many years, it is due to Mr. Symons to point out that he has not merely maintained the standard of excellence found in his annual volumes of that period, but has increased their size and usefiuness. In his paper Mr. Symons urges as a question of general policy the necessity of the formation of an hydraulic office, the early duty of a Government being "to see that all parts are completely supplied with the chief necessary of life. Englishmen," he says, "have a dread of centralisation, but in many ways they pay a long price for their dread. At present, it is not often that any town can even state before Parliament its views as to the effect upon it of what its next neighbour may be obtaining powers to do," and which, when passed by Parliamentary Committees become law, and "law for all time to come ;" he truly adds that "no one can foresee what will be the total population of the country a century hence. No one can tell where the bulk of the people will reside, nor what will be the need for water in various parts of the country," and he justly urges that special water rights, "now asked to be created, should be subject to revision, without comfensation, after the lapse of Ioo years."

Mr. E. Bailey-Denton, in his paper on "The Water Supply of Villages and Rural Districts," points out that thongh a state department exists charged with sanitary matters, the condition of our rural districts as regards water supply " is a positive disgrace," and he considers the department should have their efforts specially directed to the protection of small communities, and states that those who form the "Local Boards" and "Boards of Guardians," having jurisdiction over such districts are elected under pledges to oppose all sanitary works that will increase the rates, and that even when men of knowledge and position are elected to such posts-ontvoted by the majority they fall back to quietly agreeing with the laissez faire policy of their colleagues, and allow their constituents to continue to inhale and imbibe those germs of disease which float in the foul air that surrounds them, and are present in the only water provided for their use. Mr. Denton is evidently of the opinion that the writer has already advocated in these columns, that the Local Government Board should not only have the power to sanction local authorities pro. viding pure water and efficient sanitary arrangements, but should themselves survey the country and seek out the districts where advantage is not taken of the law, as it even now exists, and to compel the authorities to remedy the abuses and shortcomings discovered.

In the present position of our knowledge it would be difficult, and often impossible, for an engineer to advise such a rural authority, suddenly called on to provide itself with an efficient water supply, even were the legal difficulties, and cost of parliamentary struggles obliterated. Thanks to Mr. Symons, we know something of the rainfall, but as Mr. Conder and others have pointed out, our knowledge of the discharge of our rivers is lamentably small. Daily gaugings have been taken of the Thames, but no systematic examination of the quantities run off by streams draining equal areas of rocks of varying degrees of permeability have been carried out, and the necessity of such observations being taken in all our streams cannot be too highly insisted on, and should be made a matter of State care. The few observations we have were chiefly made in the last century by Rennie, if we except the comparison of chalk and elay basiı.s, made by $\mathrm{Mr}$. C. Homersham, who showed the large quantity of water absorbed by the chalk, which never appears as streams. As regards underground waters, our knowledge is also not yet sufficiently definite to safely predicate the quantity of water a given unknown district will yield. A large body of information has been published by the Underground Water Committee of the Briish Association, during the past ten years, from which the direct relation of yield to rainfall, modified by degree of permeability is clearly made out, and details given of actual supplies obtained in enormous quantities, in certain districts, but what is still required, is a systematic examination of the height of water in wells and borings throughout the kingdom, and until the seasonal variation is clearly established, the minimum yield to be obtained in a given district, during a dry year, and still more after a succession of dry years cannot be ascertained, or calculations made be depended on with any safety. Information of this class is being steadily 
accumulated in the Epsom, Croydon, and in some other districts by Mr. Baldwin Latham, C.E., who is ascertaining the seasonal variation in level of the underground waters, and the difference of cubic discharge of springs by self-recording apparatus. Valuable as are such observations for special districts for general use and public advantage, it is necessary that they should be extended to the whole country and be made by official observers for public use, and free access to the results.

In a paper on "Water from the Chalk," Mr. Joseph Lucas alluded to the work he has been doing during the past twelve years in measuring the height of the water in the wells over a large district in the Thames and Hampshire Basins, connecting together the points of observations by imaginary lines, or underground contours. $\mathrm{He}$ is able to map out with some degree of accuracy the height at which water stands in the rocks, the varying width, or proximity of the contours, indicating the varying decrease or increase of the steepness of the water gradients, i.e. the angle which the slope of the water-plane makes with the sealevel, which, as shown by the Rev. J. Clutterbuck in $184 \mathrm{I}$, varies in the chalk from 14 to 47 feet per mile. Mr. Lucas is of opinion that a comprehensive and uniform survey of the sources of watersupply, both surface and subterranean, should be carried out by the nation, and that maps should be constructed, "defining levels, areas, and quantities of water."

The Geological Survey bave done much to prepare the way for such an examination as was pointed out by Mr. Edwin Chadwick, C.B. at a previous Congress, and it is encouraging to note that the first four papers read on "Sources of Supply" at the present Conference, were contributed by three present officers, and one former officer of that staff. Mr. Whitaker's paper commenced by pointing out that ordinary geological map , in cluding the greater number as yet issued by the Geological Survey, are of little use in estimating the quantity of water obtainable from a given porous rock that may be represented on the map, and wh se water-bearing capacity may be well known, owing to the thick covering of various beds of clay, sand, gravel, loam, and alluvial silt, together called by geologists drift, which obscures the solid geology, and where the beds consist of impermeable material entirely cut off the percolation of rainfall into the pervious rock beneath. Before, therefore, any estimate can be made with any degree of accuracy, of the quantity of water capable of being yielded by a given area of permeable rock, as represented on the ordinary geological map. it is necessary to have a Drift survey, showing the actual condition of the surface. Such maps are now being issued by the Geological Survey, the various rocks, being shown by their proper colour, in the areas, when they are not overlaid by any material, the surrounding districts being coloured to indicate the nature and character of the drift deposits overlying them, distinguishing the different clays and various gravels by distinct tints. For waterworks purposes, so elaborate a classification is not requisite, and in the interesting and valuable series of maps Mr. Whitaker laid before the Congress, the results of many years of work, he has adopted the following classification :I, bare chalk; 2 , chalk covered only by beds of a permcable kind ; 3 , chalk protected by beds of mixed or varying character; 4 , chalk protected by impermeable beds. The result of Mr. Whitaker's investigations is to curtail the somewhat excessive estimates that may have been made in bygone years of the amount of chalk area available for the absorption of rain, but he states that the "chalk remains our chief water-bearing bed in the south-east of England; for though not always coming up to some of the sand-beds in permeability or porosity, it is preeminent over all other geological formations in thickness and extent of outcrop."

$\mathrm{Mr}$. Topley contributed an interesting paper on a subject he has already done good and original work, "Water Supply in its Influence on the Distribution of the Population." He shows there " is a well marked and constant relation between the outcrop of porous strata and the parish or township boundaries, the longer axes of the parishes crossing the outcrops more or less at right angles." The arrangement of parish boundaries depends upon the sites of early settlements, which were entirely controlled by the outcrop of the water-bearing beds. Mr. Topley points out that with the river, London has at present no less than four different sources of supply of water, each giving a different quality, and he notes that no city in Europe is better situated for supplying itself from is own area, but it has become so vast that all suurces have become insufficient. He notes that most of the other great capitals of Europe are als s situated on basins crpable of yielding deep well water, and instances Paris, Berlin, and Vienna.
Mr. De Rance, in a paper on "A Possible Increase of Underground Water Supply," endeavoured to show that the flow of in. termittent springs might be increased, and the violence of floods diminished by the construction of "dumb wells," through impermeable beds to pervious beds below, draining what is now unproductive rainfall, passing in destructive floods to the sea, into permeable rocks which are now not storing water owing to theis being covered by impermeable formations.

Mr. Edward Easton gives a useful résumé, gathered from his own practical experience, of well recognised principles which should govern the supply of water for domestic and other purposes, which, he justly observes, are too often neglected $\mathrm{cr}$ forgotten. He appears to have a very decided predilection for soft water in preference to hard, and alludes to the value and cheapness of the lime-softening process of Prof. Clark; as regards filtration of supplies, in which it is found impossible to altogether prevent the chance of contamination, the filtering medium should include some deodorising aoent, and he refers to the good results obtained in this direction at Wakefield by Spencer's magnetic carbide of iron, and at Antwerp by I'rof. Bischof's spongy iron; in both cases the water was much contaminated, and was rendered perfectly wholesome. Referring to the dangerous practice of storing water in cisterns, he states that after an elaborate and exhaustive examination of the waters supplied by the London water companies, by Sir Frederick Abel, assisted by Dr. Dupré, Mr. G. H. Ogston, Prof. Voelcker, and the late able chemist to the Metropolitan Board, Mr. Keates, it was found that during the session of $1877-8$, when two bills were introduced into Parliament at the instance of the Metropolitan Board of Works for purchasing the undertakings of the London water companies, and for providing a separate supply from the chalk for drinking purposes, that whilst the water in the main was in almost all cases excellent, the condition and position of the cisterns frequently rendered it utterly unfit for human consumption, a condition of affairs affording a most fruitful source of disease, and not alone confined to the dwellings of the poor, cisterns fixed on the roofs of the better class of houses being "rarely sufficiently covered, and often open to contamination from soot, dust, inroads of blackbeetles, and other abominations." Mr. Easton quotes Sir F. Bolton as to the importance of wastepipes from cisterns being carried outside each house and the end left exposed to the air, instear of communicating, as now, with the drains, from which gases flow back into the cisterns, and are absorbed by the water; but it is to be hoped, with the steadily increasing expansion of the constant service in London, this frightful evil will cease to exist. According to Colonel Sir F. Bolton's return for the month of May, the quantity of water supplied to London amounts to 32 gallons per head per day, about 20 per cent. of which, say 6 gallons, it is estimated is used for other than domestic purposes, leaving 26 gallons per head as the quantity supposed to be absolutely consumed in the houses, while long practical experience has proved that the water really required is not half that quantity, and there can be little doubt that a system of supervision like that carried out at Liverpool would have similar results. The use of Deacon's meter has reduced the consumption of water from 33 to 22 gallons per head per day; this ingenious instrument enables waste of water to be localised, and the house or place detected where the flow-off is taking place.

Mr. Easton then shows the advantage to consumer and supplier of a constant service being given to each house by water, the quantity being regulated by the rateable value of the property, but returns to the keynote of all the speakers, that " it is useless to discuss the method and conditions of supply if the sources of water are not to be preserved to us," and adds, "it is quite certain that with the immense growth of the population of this kingdom, it will not be long before this preservation becomes a pressing necessity."

Mr. Easton repeats the proposition he made in his Presidential address to the Mechanical Section of the British Association at Dublin in 1878 , which, expressing as it does a widespread feeling shared by all who have given attention to the subject, it may be well to quote at length. Mr. Easton considers that the question "of the management of rivers is of sufficient importance to make it worthy of being dealt with by new laws, to be framed in its exclusive behalf;" and that "a new department should be created-one not only endowed with powers analogous to those of the I.ocal Government Board, but charged with the duty of collecting and digesting for use all the facts and knowledge necessary for a due comprehension and satisfactory dealing with every river-basin or watershed area in the United Kingdom 
-a department which should be presided over, if not by a Cabinet Minister, at all events by a member of the Government who can be appealed to in l'arliament."

Mr. J. Mansergh, C. L., states that "altitude and geological structure of a district on the two principal factors which determine what the source of water-supply must be in each district." He divides source of supply into (a) aboveground, and (b) underground. The former he subdivides, into-r. Water talien from heads of streams by pipes, just when it ceases to be underground water, as in the case of Lancaster. 2. Water obtained from natural lakes, as in the ca;e of Glasgow. 3. Water collected from high-lying moorland watershed areas, as at Manchester. 4. Water talien from a large river flowing past a town, as the Thames and Lea, near L ondon. His second class $(b)$ he does not subdivide, and includes all waters taken from all classes of stratification; he appears to take twelve degrees of hardness of Dr. Clark's scale as the maximum limit of safety for health, and regards a pure soft supply as preferable to a pure hard supply, using the word "pure" to mean absence from organic impurity. Speaking of towns which are compelled by position, and on the score of expense to be content with a water-supply derived from an adjacent river, he states that such sources "would be inadmissible but for the great rehabilitating process which nature silently carries on in a river, and to which chemists apply the term "oxidation." " In this wonderful process the polluting organic matters which the water contains are converted by the agency of oxygen into harmless inorganic salts, and the water again becomes fit for the use of man. He here refers to the burning controversy between the two schools of opinion on this matter, which have at their heads Dr. Frankland and Dr. Meymott 'Tidy respectively; the former admits that oxidation is effective in converting the most vile contamination into a harmless condition, but does not admit it destroys the organised germs, which he believes cause the virulent zymotic discases, and which, being indestructible, may travel scores of miles in a running stream without being deprived of their fatal potency. Dr. Tidy, on the other hand, denies the existence of the germs, and affirms, after a run of a few miles, a river is fully oxygenated. Mr. Mansergh observes that, though Dr. Frankland's opponents appear to have the facts in their favour-as London, a city chiefly supplied from a polluted river, being one of the healthiest cities in the world-yet the "germ" theory is making steady advances inder the investigations and researches of competent men.

Since the London water companies have come under the official supervision of Sir Francis Bolton, large sums of money have been spent in increasing the efficiency of the subsidence tanks, by greatiy augmenting their capacity, in fact, their operations have converted them into s'orage reservoirs; from these the water is delivered into filter beds, the varieties in the construction of which, adopted by the different companies, are shown in the angle of the very interesting water pavilion erected in the Health Exhibition, under the auspices of Sir Francis Bolton, and which is full of interest to the student of the subject, and is decorated with some very artistic representations of the various waterworks on the banks of the Thames.

Any scheme of new legislation, and construction of a new department to carry out its provisions should, in the opinion of the writer, be made to include underground water supplies, the state of the law at the present time being exceedingly unsatis factory, and the decisions of parliamentary committees being uncertain and contradictory. The law places underground water in the category of wild and free creatures, that he who can catch can hold, and just as one landowner can shoot a hare on his own property that has been bred on his neighbour's land, so can he take, by sinking a well, the water that has been received on his neighbour's property, notwithstanding his neighbour may be wholly dependent upon it for water supply, and it may have been used from time immemorial, and further than this, on the principle "of doing what you like with your own," he may actually pour poison down his own well, and destroy the value of the water in the well on his neighbour's land without hindrance and without compensation. Two of the essayists at the congress referred to the recent judgment of Justice Pearson confirming this view.

Considering the opinions expressed in the papers read at this congress, and the statements made in the discussion upon them, it appears to be generally believed by those who have made the water question a special study, that the existing complex legislation, sanctioning various and often antagonistic authorities in our water-basin, is productive of the greatestharm to the community, and can only be remedied by the constitution of an hydraulic department with absolute control over streams from the ir source to their outfall; that such department should at once mako systematic arrangements for taking rain-gange observations, the gauging of the whole of our streams, and the height and seasonal variation of the water stored in the rocks beneath the surface.

\section{E. DE RANCE}

\section{THE CITY AND GUILDS OF LONDON INSTITUTE}

F ROM the Report on the Technological Examinations, 1884, we learn that a considerable increase is shown in the number of candidates at the recent examination, May 28, 1884, as compared with that of the previous year. In 1883,2397 candidates were examined, of whom 1498 passed. In 1884,3635 were examined, of whom 1829 passed. There is also shown a satisfactory increase in the number of centres at which the examinations have been held.

From the returns received at the office of the Institute in November last, it appears that 5874 persons were receiving in struction, with a view to these examinations, in the registered classes of the Institute. The number of students at the corresponding period of the previous year was 4052 , this being 585 in excess of the number in 1882 . Of the candidates who received instruction in the registered classes of the Institute, about onehalf presented themselves for examination; of the remaining candidates who came up, some had received instruction in colleges the Professors in which do not accept payment on results, whilst others had supplemented their workshop practice by private study.

This year, as last year, Glasgow heads the list of centres from which the largest number of candidates have passed, the number being $\mathbf{1 3 9}$, as compared with 123 in 1883 . Of the other centres, Manchester sent up II5 successful candidates, as against 76 in the previous year; Bolton 98 , as against II 7 ; Bradford 90 , as against $5 \mathrm{I}$; Leeds 70 , as against 64 (50 coming from the Yorkshire College, as against 43) ; Preston 59 , as against 46.

In carpentry and joinery, which was added this year to the examination programme, 369 candidates were examined, of whom 125 passed. Nottingham sent up this year for the first time I9 candidates in lace manufacture, of whom 13 succeeded in satisfying the examiner.

Examinations were held this year in 43 subjects, as against 37 in 1883 , the only subjects included in the programme in which no examinations were held being the Mechanical Preparation of Ores and Salt Manufacture.

Practical examinations were held this year for the first time in weaving and pattern designing, and in metal plate work, and owing to an alteration in the arrangements for the conduct of the Practical Examination in Mine Surveying, the results of the examination in this subject are also included in the accompanying tables.

Of the 23 candidates for honours who, besides undergoing a written examination in pattern designing and weaving, sent up specimens of their work, 13 succeeded in obtaining a certificate. In metal plate work, two candidates presented themselves for honours, but neither succeeded in obtaining the institute's certificate. In all subjects of examination, the honours certificate of the Institute is intended to be regarded as a diploma of proficiency, and is awarded in those cases only, in which the candidate shows a sound theoretical and practical knowledge of the subject.

The percentage of failures on the results of the examinations in all the subjects has increased from $37^{\circ} 5$ in 1883 to $49^{\circ} 7$ in I884. This increase in the number of failures is due to many causes, which are referred to in the separate reports of the examiners, prominent among which is the want of skill in drawing, and of previous science teaching on the part of the candidates. In many subjects, too, there is still experienced the serious want of competent teachers, which it is hoped will to some extent be remedied when the Central Institution is in working order.

The large accession to the total number of candidates is due mainly to the increase in the number of candidates in cloth and cotton manufacture, in weaving and in mechanical engineering, and to the addition of the subject of carpentry and joinery to the programme. In 28 subjects there has been an increase in the number of candidates ; in nine subjects, chiefly chemicals, 